\title{
Kann ich dem Sono-Gerät je wieder trauen?
}

_ Ich war zur Sonografie-Ausbildung im größten Krankenhaus der Stadt Chemnitz angestellt. Für den praktischen Teil durfte ich hunderte von Bildern anfertigen. Dafür untersuchte ich die Patienten zunächst klinisch, stellte dann das Ultraschallgerät ein, vermaß die Organe, sichtete Befunde, machte
Fotos zur Dokumentation und stellte Diagnosen. Am Ende ging der Befund mit geschwärzten Namen zur Kontrolle an die KV.

Bei alledem führte ein Facharzt Aufsicht. Ich wurde Dr. R. unterstellt. Der zitierte mich eines Tages zu sich an das Ultraschallgerät und befahl, ich solle die

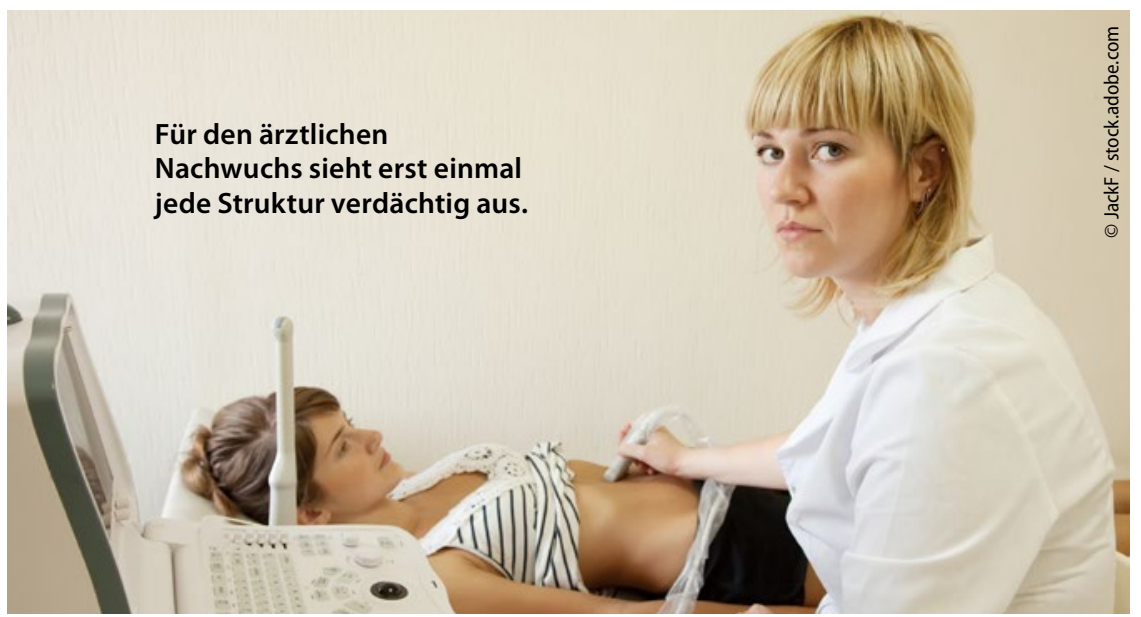

vor uns liegende junge Dame untersuchen. Daraufhin verschwand er.

Also tastete ich ihren Leib ab, fragte sie nach ihren Symptomen aus, kleckste Ultraschallgel auf ihr Abdomen und begann zu schallen. Sie klagte über Schmerzen im Unterleib, also fokussierte ich genau auf diese Stelle. Und tatsächlich: Hinter der Blase befand sich ein Tumor! Akribisch vermaß ich ihn: $2,2 \times 4,2 \mathrm{~cm}$.

Ich dokumentierte das und eilte dann zu Dr. R. ins Schwesterndienstzimmer. Dort erwartete mich die Hälfte der Belegung, eigenartig lächelnd. Ich berichtete meinem Lehrer von meinem Verdacht. Daraufhin erklärte er mir: „Junge Kollegin, das eben war ihr Gesellenstück. Das machen wir mit allen Praktikanten. Sie haben bestanden!“

Er lächelte spitzbübisch. Dann fügte er hinzu: „Aber was Sie da vermessen haben, war kein Tumor. Das war der eingeführte Tampon der Dame.“

Dr. Benita Martin, Chemnitz

\section{Ein mündiger Patient flieht aus der Klinik}

_ „Wenn sich einer mit Marcumar auskennt, dann bin ich das!“ Das war das Fazit einer Geschichte, die mir ein erboster Patient erzählte. „Darum bin ich dann einfach nach Hause gegangen und habe die Sache selber in die Hand genommen“, fügte er hinzu. „Verschreiben Sie mir bitte Heparin?"

Natürlich tat ich das, schließlich hatte ich soeben eine hanebüchene $\mathrm{Ge}$ schichte gehört. Der gute Mann hatte sich für eine Koloskopie mit Polypenentfernung ins Krankenhaus begeben und dafür sein Marcumar absetzen müssen. Am Tag nach dem Eingriff hat man ihm zum Aufdosieren wieder drei Tabletten gegeben. Die Heparinspritze jedoch hatte man ihm verweigert. „Sie haben doch Marcumar!", hieß es nicht nur von der Schwester sondern auch von der Stationsärztin.

Sein Einwand, dass es ja nun einige Tage dauern würde, bis die Gerinnung ausreichend herabgesetzt wäre, um ihn als Patienten mit Vorhofflimmern angemessen zu schützen, wurde abgeschmet- tert. Schließlich bekam er „aus lauter Gnade“ eine Spritze. Am nächsten Tag allerdings gab es keine mehr, allen Bitten und allem Betteln zum Trotz.

Daraufhin packte er seine Sachen und suchte das Weite. „Zurecht!“, dachte ich, während ich das Heparin-Rezept schrieb. Sein INR-Wert war immer noch deutlich zu niedrig. Ich verabschiedete den nunmehr zufriedenen Patienten herzlich. Und dann rief ich den internistischen Klinikchef an.

Dr. Frauke Höllering, Arnsberg 